\title{
Derived Storage Allocation Rules to Meet Shared Water Demands for Optimal Operation of an Inter-basin Multi-reservoir Water Supply System
}

\author{
Fang Wan $^{1}$, Yu Wang ${ }^{2}$, Lingfeng Xiao ${ }^{1}$, and Qihui Chai ${ }^{1}$ \\ ${ }^{1}$ North China University of Water Resources and Electric Power \\ ${ }^{2}$ Yellow River Engineering Consulting Co Ltd
}

June 22, 2021

\begin{abstract}
The priority principle of storage allocation rules of serial cascade reservoirs within an inter-basin water supply can reduce water loss and reduce water supply times. Reasonable balancing curves for reservoirs in parallel are proposed and the proportional distribution of water is determined to illustrate the optimal allocation rule for different scheduling periods of reservoirs. The mutation point and slope are used to describe the segmentation of reservoirs in parallel. In addition, the optimization model is established with the objective function to minimize times of water shortage while the particle swarm optimization algorithm based on the immune evolutionary algorithm is applied to calibrate the balancing curves. Finally, the relative optimal water supply rule is obtained, providing a larger water supply capacity and higher storage synchronization of member reservoirs. The reservoir groups downstream of Luan River are used as an example, with the results showing that the suggested method can effectively improve the operational performance and meet shared water demands in an inter-basin multi-reservoir. This article highlights the superior results obtained compared to the current storage allocation rules to meet shared water demands.
\end{abstract}

\section{Hosted file}

New Derived storage allocation rules.docx available at https://authorea.com/users/421074/ articles/527236-derived-storage-allocation-rules-to-meet-shared-water-demands-foroptimal-operation-of-an-inter-basin-multi-reservoir-water-supply-system

\section{Hosted file}

Tables.docx available at https://authorea.com/users/421074/articles/527236-derived-storageallocation-rules-to-meet-shared-water-demands-for-optimal-operation-of-an-inter-basinmulti-reservoir-water-supply-system

\section{Hosted file}

Figures.docx available at https://authorea.com/users/421074/articles/527236-derived-storageallocation-rules-to-meet-shared-water-demands-for-optimal-operation-of-an-inter-basinmulti-reservoir-water-supply-system 